\title{
Wafer Dosage Form
}

National Cancer Institute

\section{Source}

National Cancer Institute. Wafer Dosage Form. NCI Thesaurus. Code C43003.

A solid composed of a thin slice of material that contain active and/or inert ingredient(s). 